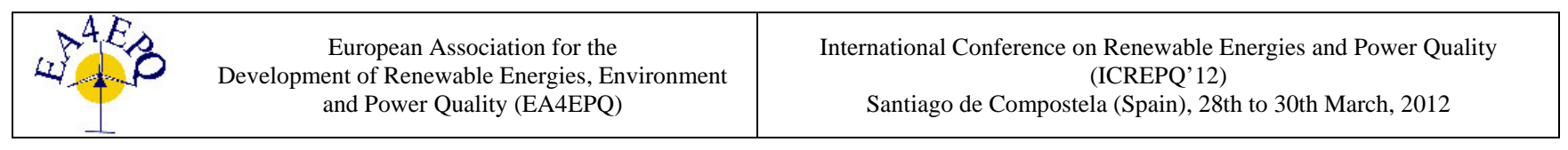

\title{
Development of Multifunctional Platform for Education, Research and Promotion of Renewable Energy Sources
}

\author{
V. Stoilkov, D. Dimitrov, M. Stankovski and H. Spasevska \\ Faculty of Electrical Engineering and Information Technologies \\ Sts Cyril and Methodius University in Skopje \\ 1000 Skopje (Macedonia) \\ Phone number: +389 23062 224, Fax number: +389 23064 262, \\ e-mails: stoilkov@feit.ukim.edu.mk, ddimitar@feit.ukim.edu.mk,milestk@feit.ukim.edu.mk, \\ hristina@feit.ukim.edu.mk
}

\begin{abstract}
The development of renewable energy sources (RES) in recent decades faced a rapid growth, especially in wind and solar applications. During the implementation of RES from different aspects, many issues have arisen, especially with technology development, grid connection and power quality. The paper is focusing on a project for creation a multifunctional platform with basic aims directed to educational, research and promotional activities for renewable energy sources in general and with special attention to solar/wind applications and energy utilization in both: grid connected and stand-alone applications.
\end{abstract}

\section{Key words}

Renewable energy sources, hybrid systems, wind energy, solar energy.

\section{Introduction}

The Faculty of Electrical Engineering and Information Technologies (FEIT) as the unit of Sts Cyril and Methodius University in Skopje, Republic of Macedonia, according to its continual mission to follow and implement the advanced technologies, in March 2011 started to develop an idea for an ambitious project for construction of a small range multifunction power plant for electricity generation from solar and wind energy, as hybrid renewable energy sources (RES) system.

The main consisting parts of the platform are: photovoltaic (PV) generator, wind generator, batteries, diesel generating set, etc. Within this, the modules of the PV generator will be placed on a metal mounting construction, which will be also aimed to make shelters one of the car parking areas within the FEIT campus, on an area of about $1000 \mathrm{~m}^{2}$. This will enable a multifunctional purpose of the object, without occupying any active space. The wind generator will be placed in the vicinity of the PV generator. In such consideration, both PV and wind generators can operate autonomously, as well as in one hybrid system. The total installed power of the PV generator will be about $80 \mathrm{kWp}$, and the rated power of the wind generator will be in the range of 3 $5 \mathrm{~kW}$.

\section{The Project Aims}

After the commissioning, both power plants are expected to act as a multifunctional platform for a number of educational, research and developing activities connected to exploitation of RES, with a special stress on a solar and wind energy use. In that way, one part of the power plant will be connected to the public grid (approx 50 $\mathrm{kWp}$ ), the second part (approx $15 \mathrm{kWp}$ ) will be operating as independent source for covering the campus electricity needs like lighting and powering the campus watering system and the third part (approx $15 \mathrm{kWp} \mathrm{PV}$ and $3 \mathrm{~kW}$ wind) will be operating in common as a hybrid system for indirect battery/inverter use for car charging etc. All the three parts will be used for educational and research activities of the enrolled students, as well as for promotional activities for the wider public in favor of renewable energy sources.

For placement of the supplemental equipment (inverters, monitoring system, measuring instruments), as well as to provide a room for a proper educational and research work, building of an object located in the vicinity or in the indoor of the mounting structure is planned.

The PV plant will be consisted of several sections, where PV modules with different cell technologies and different manufacturers will be integrated. The metal construction of the mounts will be designed to enable tilting of the PV modules to a specified tilt angle in order to obtain the optimal energy yield.

The project will emphasize: the design of the panels with PV modules, design of the wind generators, design of the system of inverters for adapting to the grid conditions / consumers, sun tracking system of the PV panels, aspects of hybrid operation of the PV generator, wind generator, batteries and the diesel generator, as well as, informationcommunication system for a long-distance control etc. The designing and the sizing of the plants will be carried out through a co-operative work of a number of professors, students from undergraduate, MSc and PhD studies, including almost all research fields that the Faculty deals with. 
The project will involve participants from the partner companies. In that manner, for issues connected to the different aspects of the Project, FEIT will also co-operate with relevant experts from the other technical faculties within the University. Apart of these, in order to transfer their positive experiences in the field, the Project will involve partners from other Universities from abroad.

\section{Short Analysis to the General Impacts of the Project}

Energy situation in Macedonia is very complex, under conditions of transformation process towards implementation of European standards, policies and fulfillment of some conditions in energy sector. The governmental strategy is presently directed to increase the investments in energy efficiency, energy saving and utilization of renewable energy sources. To overcome some of the problems and to improve this strategy, it is necessary to disseminate widely transparent energy policies and to establish appropriate knowledge, sharing and cooperating among all organizations involved and interested in Macedonian energy sector. Therefore, implementation of a Multifunctional System for Education, Research and Promotion of Renewable Energy will support links among education, training and innovation institutions, government and other appropriate institutions to ensure highest possible positive impact for improving the research, application and implementation of RES in the country.

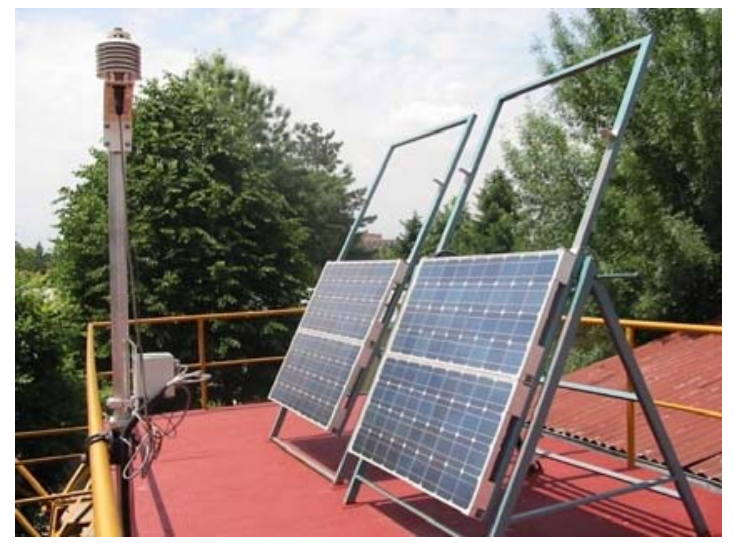

Fig. 1. Existing small PV lab at the premises of FEIT

\section{Results}

For obtaining optimal disposition of PV modules, several simulations have been performed with PVSYST software package for different number/types of levels, number of string layers, number of modules in one string as well as the module orientation.

The optimal disposition of the PV modules and stair-type platform structure as car parking shelter are presented in Fig.2. The PV modules are distributed in three groups, each consisting of 5 levels two-layer strings of modules. Each two-layer string is consisted of 22 modules with $230 \mathrm{Wp}$ installed power. The total number of modules in each group is 110 , totaling installed $25.3 \mathrm{kWp}$ per group or $75.9 \mathrm{kWp}$ for the whole platform.
For the purpose of increased efficiency and research activities, the possibility of changing the tilting angle will be provided for each string of modules.

The transposition factors for specified location for periods of one month (December) as well as for the whole year, with different horizontal global irradiation is given in Fig. 3.

The beam shading curves for twelve typical dates during the year for $65^{\circ}$ strings' tilting are presented in Fig.4.

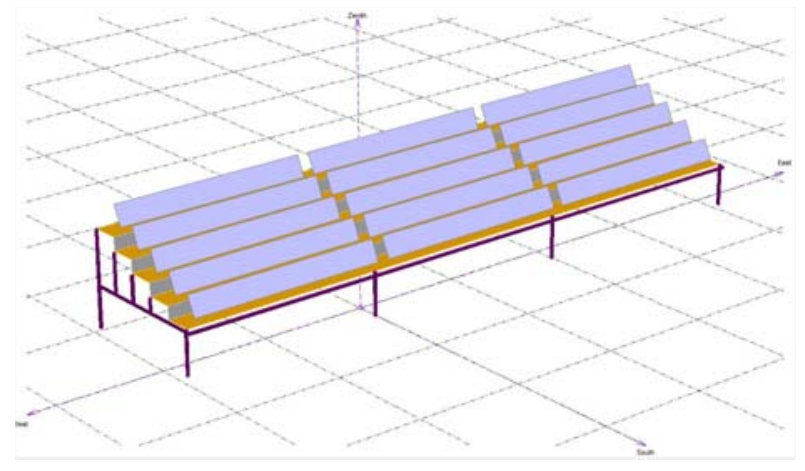

Fig. 2. The disposition of PV modules and panel platform structure as car parking shelter
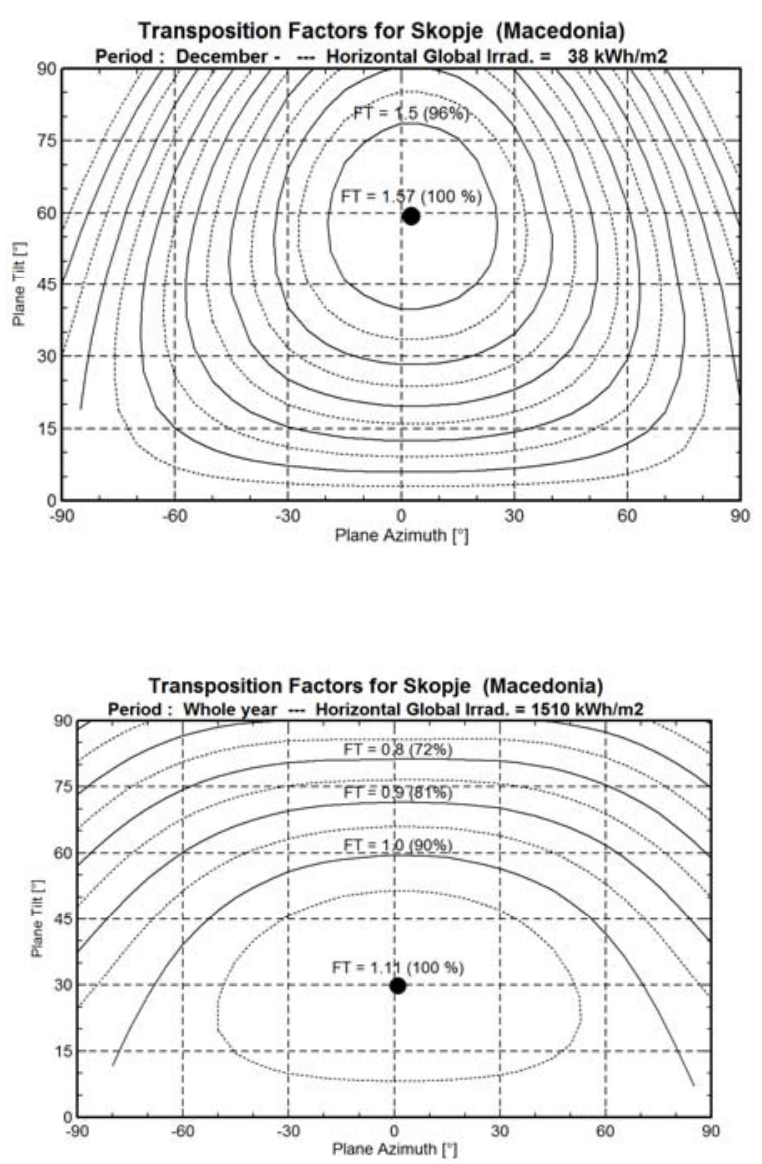

Fig. 3. The transposition factors for periods of one month (December) and whole year 


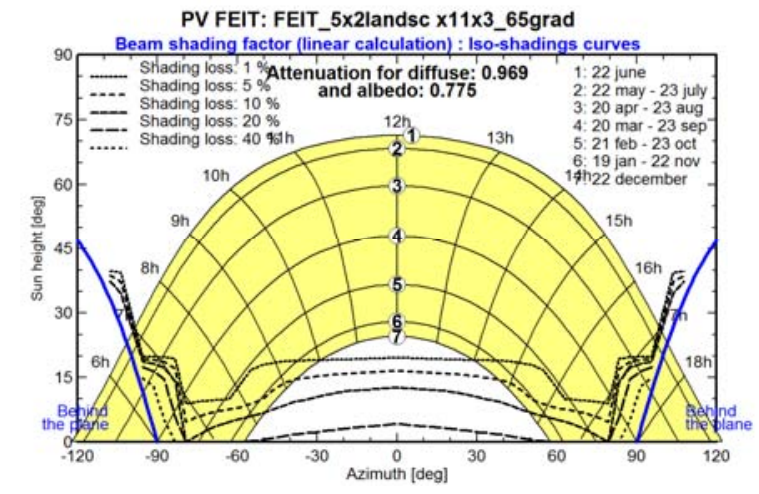

Fig. 4. The beam shading curves for 12 typical dates during the year for $65^{\circ}$ strings' tilting

\section{Conclusion}

Proposed project will enable high level of competence and capacities building of UKIM-FEIT through implementation of a Multifunctional System for Education, Research and Promotion of Renewable Energy, as the first and unique system of this kind in Macedonia. This System can be recognized by government, industries and scientific community in Macedonia and abroad as a tool for education, research, and promotion of RES.
The strategic aim of the System will be strengthening collaboration among scientific institutions and industrial companies in Macedonia and abroad, having the same research, developing and application interest in the field of RES. This will improve regional cooperation strategies, elaboration of concepts aimed at sustainable development and societal innovation.

\section{References}

[1] Y. Meng and Y. Dong, "Application and promotion of PV DC conversion system in university laboratorios", in Proc. ICMREE 2011, Shanghai, (2011), pp. 187-190.

[2] J. Hamar, R.K. Jardan, I. Nagy and H. Ohsaki, "Virtual laboratory for combined solar energy system", in Proc. EPE2007, Aalborg, (2007), pp. 1 - 8.

[3] T. Hirose and H. Matsuo, "Standalone Hybrid Wind-Solar Power Generation System Applying Dump Power Control Without Dump Load”, IEEE Industrial Electronics Trans. On. Vol. 59. Issue: 2, pp. 988 - 997.

[4] R. Pecen and A.Nayir: "Design and implementation of a 12 $\mathrm{kW}$ wind-solar distributed power and instrumentation system as an educational test bed for Electrical Engineering Technology students", in Proc. MEPS2010, Wroclaw, (2010) pp. 1 - 6 . 